STOMACH

\title{
Effect of a somatostatin analogue on gastric motor and sensory functions in healthy humans
}

\author{
A Foxx-Orenstein, M Camilleri, D Stephens, D Burton
}

Gut 2003;52:1555-1561

See end of article for authors' affiliations

....................

Correspondence to: Professor M Camilleri, Mayo Clinic, Charlton 8110,200 First Street SW, Rochester, MN 55905 , USA; camilleri.michael@ mayo.edu

Accepted for publication 28 June 2003

\begin{abstract}
Background: Pharmacological approaches to alter satiation may have an impact on functional upper gastrointestinal disorders and potentially change food intake in obesity.

Aim: Our aim was to compare the effects of two doses of octreotide and placebo on postprandial symptoms, gastric accommodation, and gastric emptying using validated non-invasive techniques.

Methods: In a randomised, parallel group, two dose, double blind, placebo controlled study, 39 healthy participants (13 per group) were randomised to 30 or $100 \mu \mathrm{g}$ octreotide or placebo, administered subcutaneously, 30 minutes before each study. Studies were performed on three separate days and

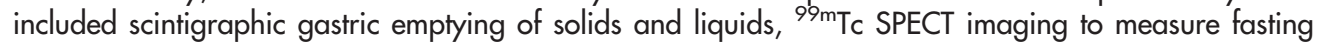
stomach volume and gastric accommodation following a $300 \mathrm{ml}$ Ensure meal, and a standardised nutrient drink test to measure maximum tolerated volume and postprandial symptoms.

Results: Relative to placebo, both doses of octreotide delayed gastric emptying of solids (not liquids), increased fasting gastric volume, reduced the change in gastric volume post meal, and decreased the sensation of fullness after a satiating meal.

Conclusion: The somatostatin analogue octreotide significantly alters human gastric functions, including inhibition of the normal reflex responses of gastric volume increase and emptying of the meal. These pharmacological effects suggest studies of the medication in disorders of satiation, including obesity and dyspepsia, are warranted.
\end{abstract}

$\mathrm{P}$ harmacological approaches to alter satiation may have an impact on functional upper gastrointestinal disorders and potentially change food intake in obesity. One of the modulators of upper gastrointestinal function is the neurotransmitter somatostatin. Somatostatin exerts physiological actions via a family of six $G$ protein coupled receptors (sstl, sst2A, sst2B, sst3, sst4, sst5). ${ }^{1}$ The cyclised analogue octapeptide, octreotide, binds preferentially to type 2 receptors. Several studies have addressed the effects of somatostatin or the synthetic analogue octreotide on human gastrointestinal motor functions in health and disease states. $^{2-9}$ The native hormone, somatostatin, induces migrating motor complexes in the small intestine, and this is synchronised with secretory and motor activities of the gall bladder and pancreas. ${ }^{10-12}$ At a dose of $50 \mu$ g subcutaneously, octreotide induces inhibition of antral motor function, and induces phase III-like complexes in the small bowel in all patients with functional or organic motility disorders of the upper gut as well as in healthy controls. ${ }^{2}$ Following the activity front, there is a prolonged period of quiescence or a second, usually normally propagated activity, front in $30 \%$ of subjects. ${ }^{2}$ This may contribute to the delay in small bowel transit previously reported. ${ }^{367}$

In fact, the effects of octreotide on transit through the human gastrointestinal tract are most prominent in the small intestine. ${ }^{2-9}$ Radiolabelled solid residue traverses the small bowel at rates that are twice as slow with octreotide ( $50 \mu \mathrm{g}$ three times daily) compared with placebo treatment in healthy individuals. ${ }^{3}$ Thus the somatostatin analogue affects predominantly small bowel transit and to date its therapeutic application has reflected this function (for example, in the short bowel syndrome, ${ }^{7}$ diabetic diarrhoea, ${ }^{4}$ or dumping syndrome). ${ }^{8}$ Octreotide is effective in slowing gastric and orocaecal transit in irritable bowel syndrome ${ }^{6}$ and this is accompanied by inhibition of several gastroenteropancreatic hormones that are involved in mediating some of the fluid fluxes and motor responses to meal ingestion. ${ }^{56}$

The inhibitory effects of somatostatin on smooth muscle function in the vasculature ${ }^{13}$ has led to important advances in the treatment of portal hypertension. Octreotide inhibited colonic tone in the postprandial period, ${ }^{3}$ and reduced colonic sensation in healthy volunteers ${ }^{14}$ and in patients with irritable bowel syndrome. ${ }^{15}{ }^{16}$ Intestinal mechanosensitive afferents are modulated by somatostatin. ${ }^{17}{ }^{18}$ The effect of octreotide on human gastric sensation and accommodation is unclear. In two small studies using invasive techniques (barostat balloon), inconsistent effects on gastric tone, compliance, and sensation were noted with somatostatin infusion and octreotide. ${ }^{19} 20$

Our aim was to use non-invasive validated techniques to compare the effects of two doses of the somatostatin analogue octreotide and placebo on postprandial symptoms, gastric accommodation, and gastric emptying in healthy human volunteers.

\section{MATERIALS AND METHODS \\ Experimental design and participants}

This randomised, parallel group, two dose (30 and $100 \mu \mathrm{g})$, double blind, placebo controlled, single centre study was conducted in 39 healthy volunteers between the ages of 18 and 65 years recruited from the local community through public advertisement. Thirteen participants were randomly allocated to each treatment group in the parallel design study. Exclusion criteria included abdominal surgery other than appendectomy, positive symptoms on an abridged bowel disease questionnaire, use of medications that may

Abbreviations: SPECT, single photon emission computed tomography; VAS, visual analogue scale; IQR, interquartile range 
alter gastrointestinal activity or interact with study medications, history of gall stone or biliary tract disease, known intolerance or allergy to eggs, any gastrointestinal illness or systemic condition that could affect gastrointestinal activity, or any over the counter medications taken within seven days of the study. The study was approved by Mayo Foundation's Institutional Review Board. Eligible subjects gave their written consent and were randomised to receive either octreotide (Sandostatin; Novartis, East Hanover, New Jersey, USA) $30 \mu \mathrm{g}$ or $100 \mu \mathrm{g}$, or saline (placebo).

\section{Study medications}

Following the initial screening, subjects were randomised to receive $30 \mu \mathrm{g}$ octreotide, $100 \mu \mathrm{g}$ octreotide, or placebo. Compared with the native hormone somatostatin, the cyclised peptide analogue octreotide is highly resistant to enzymatic degradation and has a prolonged plasma half life of approximately 100 minutes in humans. ${ }^{21}$ The volume of distribution of octreotide ranges from 18 to 30 litres. Calculated serum distribution half life ranges from 72 to 98 minutes. In blood, octreotide is mainly distributed in plasma, $65 \%$ being bound to lipoproteins. After subcutaneous injection, absorption appears rapid and complete and bioavailability is approximately $100 \%$. Mean peak plasma concentrations are between 2 and $4 \mu \mathrm{g} / \mathrm{l}$ in patients receiving $50-100 \mu \mathrm{g}$.

The study medications were prepared and dispensed by the Research Pharmacy of the Mayo General Clinical Research Center in a randomised order; all of the study medications were identical in appearance. The clinical investigators, study personnel, and volunteers were blinded to the treatment assignments until after the data analysis was complete.

\section{Study procedures}

The study was performed on three non-consecutive days with one test performed on each study day; the order of the tests was not standardised to avoid an order effect. Subjects presented to the study centre in the fasting state on each day. Randomly assigned blindly allocated doses of octreotide or placebo were administered subcutaneously by a study nurse 30 minutes before the start of each test.

A standard scintigraphic gastric emptying test ${ }^{22}$ was performed on one day. A ${ }^{99} \mathrm{~m}$ Tc sulphur colloid labelled egg meal was used to assess gastric emptying. The eggs were served with one slice of buttered bread and an eight ounce glass of 1\% milk (total calories: $296 \mathrm{kcal}$, 32\% protein, 35\% fat, 33\% carbohydrate). Anterior and posterior gamma camera images were obtained over four hours of testing, at 15 minute intervals for two hours, and at 30 minute intervals for the final two hours to assess gastric emptying.

On a separate day, subjects underwent single photon emission computed tomography (SPECT) imaging to evaluate fasting gastric volume and postprandial gastric volumes. The SPECT technique involves infusion of ${ }^{99 \mathrm{~m}} \mathrm{Tc}$ that is taken up by the gastric mucosa. Dynamic tomographic images are obtained with the SPECT camera, allowing visualisation of three dimensional images of the stomach. The images are 16 minutes in duration, and three were obtained: one during fasting (after administration of the subcutaneous injection), and two sequentially after the standard $300 \mathrm{ml}$ Ensure meal. The ${ }^{99 \mathrm{~m}}$ TC SPECT technique accurately and reliably demonstrates changes in gastric volume. ${ }^{23} 24$. Briefly, tomographic images of the gastric wall are obtained throughout the long axis of the stomach using a dual head gamma camera (SMV SPECT System; SMV America, Twinsburg, Ohio, USA) that rotates around the body. This allows assessment of the radiolabelled circumference of the gastric wall rather than the intragastric content. Using the AVW 3.0 (Biomedical
Imaging Resource, Mayo Foundation, Rochester, Minnesota, USA) image processing libraries, a three dimensional rendering of the stomach is obtained and its volume $(\mathrm{ml})$ calculated. Radiation exposures from the scintigraphic gastric emptying and SPECT gastric accommodation tests were previously published in detail. ${ }^{25}$ Radiation effective doses $\left(\mathrm{H}_{\mathrm{e}}\right)$ are 90 mrem for gastric emptying and $619 \mathrm{mrem}$ for gastric accommodation tests. ${ }^{25}$

On a separate day, participants underwent the "satiety test" to assess postprandial symptoms and gastric emptying of nutrient liquids. An adaptation of the method of Tack et al was used to measure the maximum tolerated volume. ${ }^{26}$ Subjects ingested $30 \mathrm{ml}$ of a nutrient drink (Ensure $1 \mathrm{kcal} /$ $\mathrm{ml})$ per minute. The cup containing the nutrient drink was filled using a constant rate perfusion pump, and participants were required to maintain intake at the filling rate until the maximum tolerated volume was reached. Participants scored their satiation (feeling of fullness) at five minute intervals using a graphic rating scale that combined verbal descriptors on a scale graded $0-5 \quad(0=$ no symptoms, $5=$ maximum satiation). Participants stopped meal intake when a score of 5 was reached. The first glass of the nutrient drink was radiolabelled with $0.05 \mathrm{mCi}$ of ${ }^{111} \mathrm{In}$-DTPA to facilitate measurement of gastric emptying of liquid; scintigraphic scans were performed at 10 minute intervals in the first hour, 15 minutes during the second hour, and at 30 minute intervals for the third hour.

Thirty minutes after reaching the maximum tolerated volume, participants scored their symptoms of bloating, fullness, nausea, and pain using $100 \mathrm{~mm}$ visual analogue scales (VAS) anchored with the words "unnoticeable" and "unbearable" at the left and right ends (that is, maximum score 100 for each symptom). The aggregate symptom score was defined as the sum of the VAS scores for each symptom (that is, maximum score 400). We have reported normal values for the nutrient drink test $\mathrm{t}^{27}$ in adolescents and adults.

Gastric accommodation is a robust vagally mediated reflex in health which results in reduced gastric tone, increased compliance, and increased gastric volume. Accommodation allows ingestion of large volumes of solids or liquids without inducing postprandial symptoms. An abnormally low postprandial gastric volume may contribute to the development of symptoms in patients with functional dyspepsia, post vagotomy surgery, post fundoplication dyspepsia, rumination syndrome, and diabetic vagal neuropathy. ${ }^{23} 24$ 27-29

A non-invasive method has been developed ${ }^{30}$ and validated $^{3}$ in our laboratory to measure fasting and postprandial gastric volumes using an intravenous injection of ${ }^{99 \mathrm{~m}} \mathrm{Tc}$ pertechnetate $\left({ }^{99 \mathrm{~m}_{\mathrm{TCO}}}{ }^{-}\right)$and imaging with SPECT. Tomographic images were acquired on a large field of view dual headed gamma camera system (SMV SPECT System; SMV America). Gastric volumes were measured using the SPECT-ANALYZE PC 2.5 (Biomedical Imaging Resource) software system. ${ }^{30}$ There is a high degree of correlation between volumes measured by SPECT and barostat balloon in response to distension and to a meal. ${ }^{3}$

The gastric mucosa can take up intravenously administered ${ }^{99 \mathrm{~m}} \mathrm{Tc}$ pertechnetate $\left({ }^{99 \mathrm{~m}} \mathrm{TcO}_{4}{ }^{-}\right)$from the circulating blood pool. Starting 10 minutes after intravenous injection of $10 \mathrm{mCi}{ }^{99} \mathrm{TCO}_{4}{ }^{-}$, imaging was performed during fasting and for a total of 32 minutes after ingestion of a $300 \mathrm{ml}$ nutrient drink (Ensure $1 \mathrm{kcal} / \mathrm{ml}$ ) through a straw. Gastric volumes were assessed during two postprandial periods: 0-10 minutes and 10-20 minutes following the meal. Transaxial images of the stomach were rendered with ANALYZE to reconstruct three dimensional images and to measure gastric volumes during the fasting and postprandial 


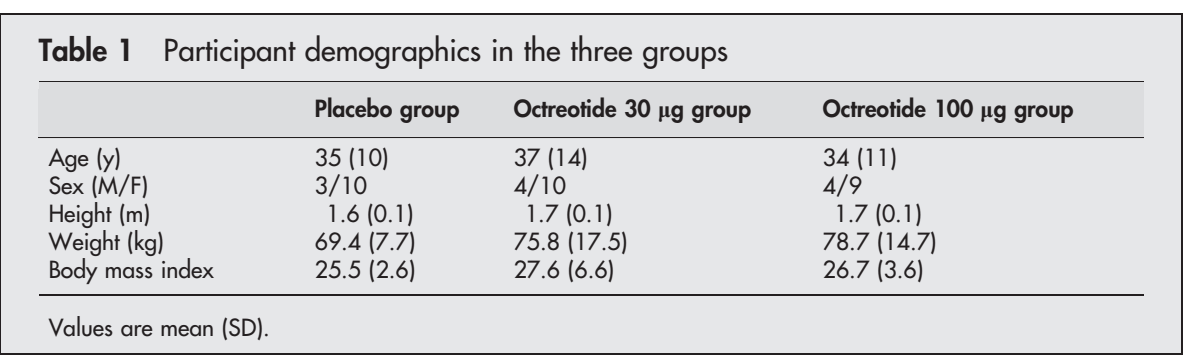

periods. Volume changes and ratios between the fasting and postprandial periods were calculated.

\section{Data analysis}

The geometric mean of counts in the anterior and posterior gastric regions of interest was used to estimate the gastric emptying $\mathrm{T}_{1 / 2}$ of solids and liquids. A second important transit end point was lag time, or time taken for emptying of $10 \%$ of the solid meal.

The maximum tolerated volume of nutrient drink ingested was recorded. Individual symptoms scores (maximum score 100) for bloating, fullness, nausea, and pain and the aggregate symptom score, the sum of the individual symptom scores (maximum score 400), were documented.

Fasting and postprandial gastric volumes were measured by ANALYZE using reconstructed three dimensional images of the stomach. Two time periods, 0-16 and 17-32 minutes following the meal, were assessed and the average of these two postprandial gastric volume estimates calculated. While it is possible to separate the stomach volume into a proximal and distal segment ${ }^{23}$ using this technique (for example, based on the location of the incisura), anatomical variations between individuals (for example, the shape of the stomach, clarity of the incisura, axis of the stomach) make any division arbitrary and potentially erratic as a means to compare the
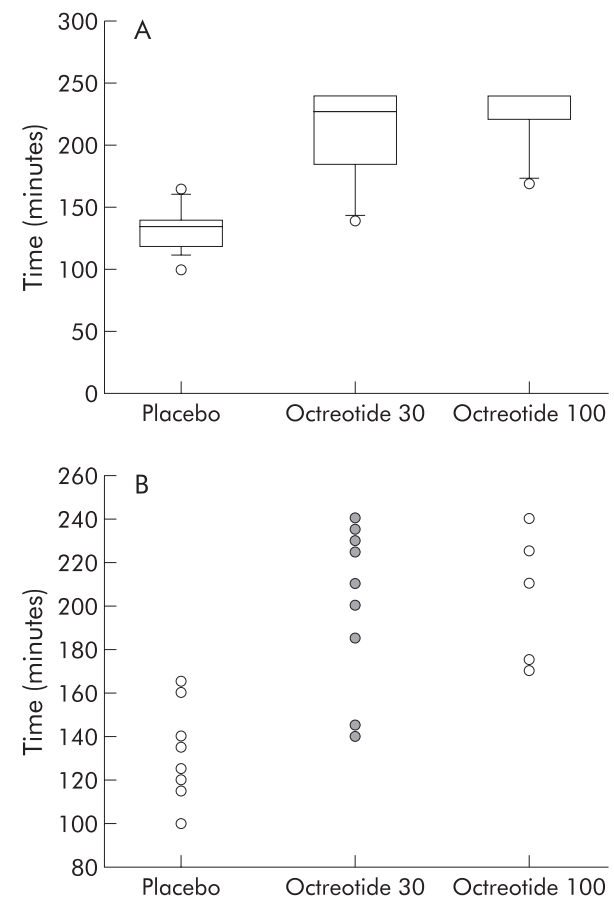

Figure 1 Effect of octreotide 30 and $100 \mu \mathrm{g}$ compared with placebo on gastric half emptying time for solids. (A) Median, interquartile range, and full range. (B) Scatterplot of all data. Note that both doses of octreotide retarded gastric emptying. effects of octreotide on different gastric regions. Hence our choice to evaluate effects on the entire stomach rather than subregions of the stomach.

\section{Statistical methods}

The primary end points selected for analysis were maximal volume of Ensure tolerated; the aggregate symptom score 30 minutes after ingestion of Ensure; $\mathrm{T}_{1 / 2}$ of gastric emptying of solid and nutrient liquid; and fasting gastric volume and change in gastric volume following the standardised meal. Secondary end points were individual postprandial symptoms scores.

The effects of the three treatments on transit parameters, gastric volumes, and symptom scores were compared using analysis of variance on ranks (Kruskal-Wallis test). Two specific (a priori) contrasts (at $\alpha=0.05$ ) among treatment groups based on the ANOVA on ranks were examined (overall drug $v$ placebo and each dose $(30,100 \mu \mathrm{g})$ of octreotide $v$ placebo) using an appropriate multiple comparison procedure (Dunn's method). All analyses were performed using SigmaStat (version 2.0 for Windows 95, NT \&3.1, 1997; SPSS Inc., Chicago, Illinois, USA).

\section{Sample size assessment}

With 13 subjects per group, we anticipated the analysis of variance would provide $80 \%$ power to detect pairwise
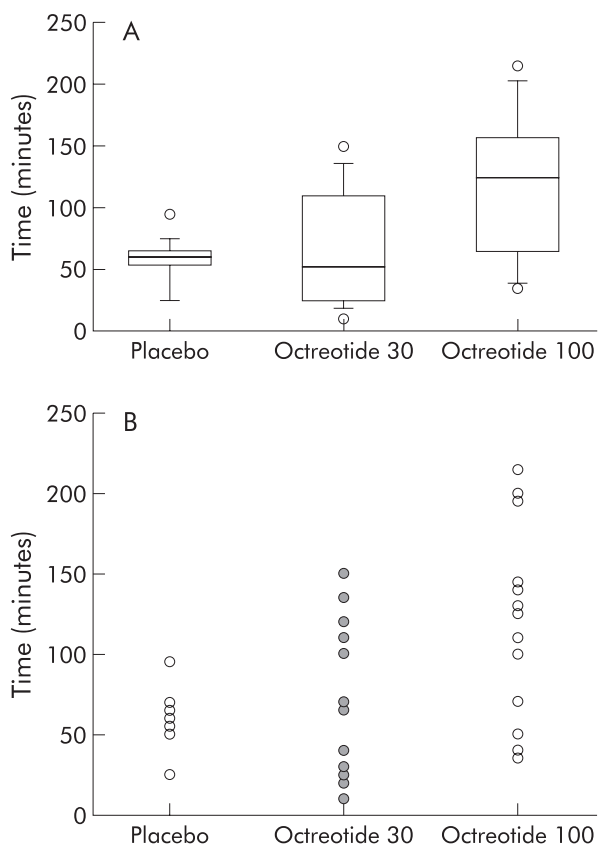

Figure 2 Effect of octreotide 30 and $100 \mu \mathrm{g}$ compared with placebo on gastric emptying lag time (time at $10 \%$ emptied) for solids. (A) Median, interquartile range, and full range. (B) Scatterplot of all data. Note that only octreotide $100 \mu \mathrm{g}$ prolonged gastric emptying lag time. 
A
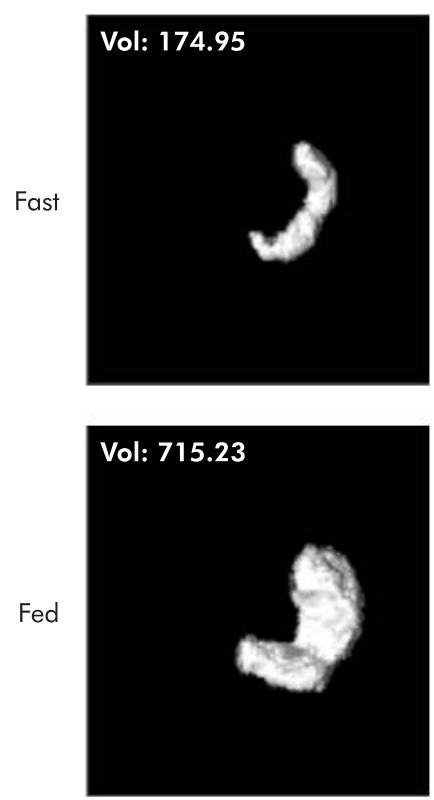

Delta volume $=540.3$
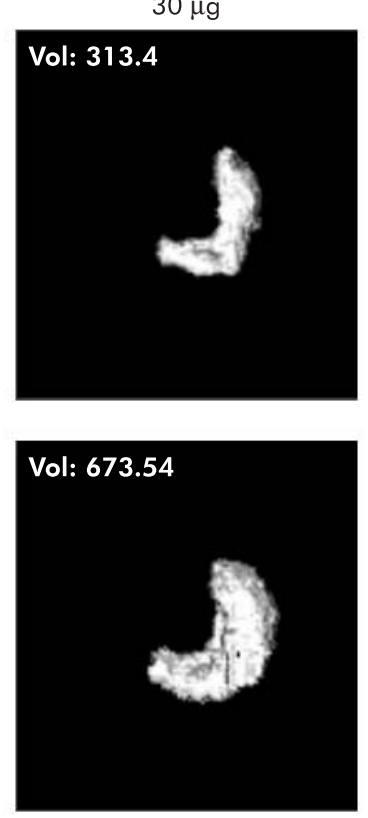

Delta volume $=360.1$
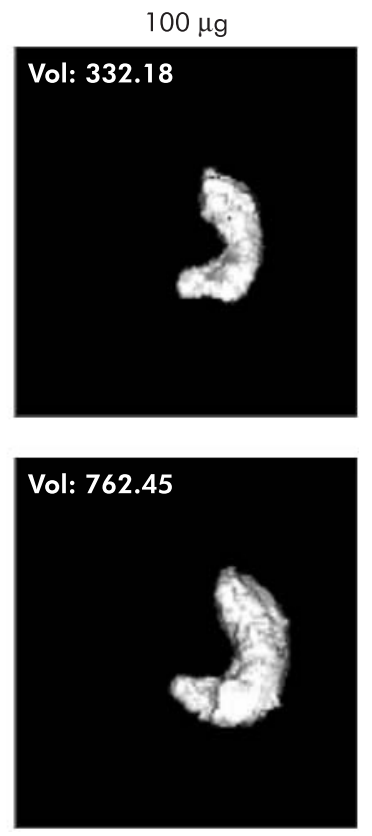

Delta volume $=430.3$
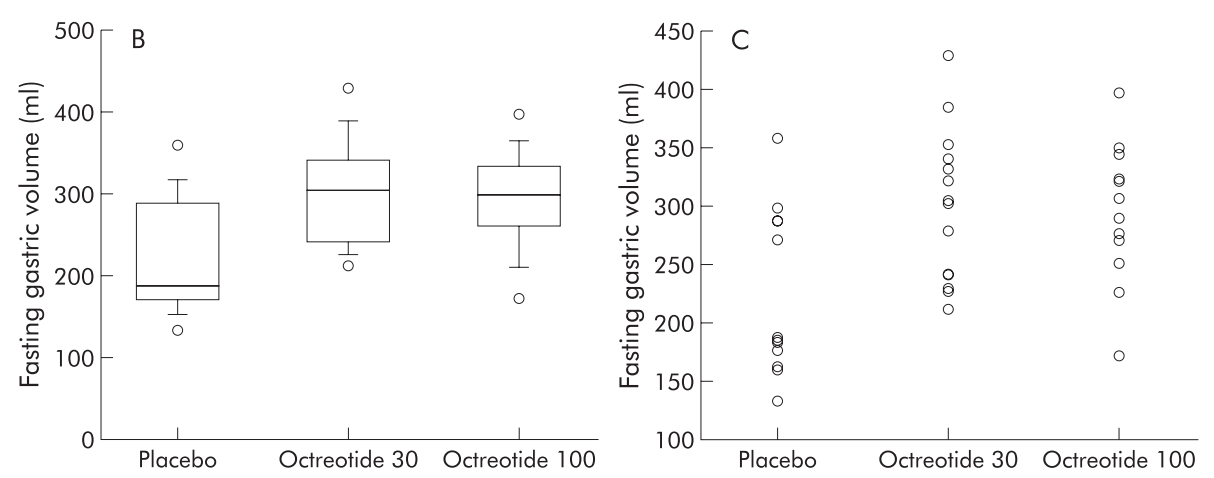

Figure 3 Effect of octreotide on gastric volumes measured by single photon emission computed tomography imaging after ${ }^{99 \mathrm{~m} T c}$ pertechnetate injection. (A) Reconstructed images of the stomach during fasting and postprandially after placebo and octreotide 30 and $100 \mu \mathrm{g}$ treatment. (B) Median, interquartile range, and full range of fasting gastric volumes. (C) Scatterplot of all data. Note that both doses of octreotide retarded the increase in fasting gastric volumes.

differences using a pooled estimate of variation across all three groups, based on previously published data for satiety testing and gastric accommodation in healthy volunteers and in patients with non-ulcer dyspepsia, ${ }^{24} 25$ and scintigraphic transit studies. ${ }^{22}$

\section{RESULTS}

\section{Participant characteristics}

Forty volunteers were screened and 39 were enrolled into the study. One volunteer who was screened developed influenza symptoms and was withdrawn from the study before randomisation. All 39 volunteers completed the study. Volunteer demographics are shown in table 1. No significant differences in age, sex, height, weight, or body mass index were detected between the groups.

\section{Effect of octreotide on gastric emptying of solids and liquids}

Octreotide delayed gastric emptying $\mathrm{T}_{1 / 2}(\mathrm{p}<0.001)$ and lag time $(\mathrm{p}=0.016)$ relative to placebo (figs 1,2$)$; this retardation of $T_{1 / 2}$ was significant for both doses of octreotide tested $(\mathrm{p}<0.05$ with correction for multiple comparisons) but only the $100 \mu \mathrm{g}$ dose prolonged the lag time for emptying of solids.
The effect of octreotide on liquid emptying $\mathrm{T}_{1 / 2}$ was not significant (placebo: median 180 minutes (interquartile range (IQR) 133-180); octreotide $30 \mu \mathrm{g}$ : 163 minutes (IQR 85-180); octreotide $100 \mu \mathrm{g}$ : 80 minutes (IQR 42-180)).

\section{Effect of octreotide on gastric volumes}

Octreotide increased fasting gastric volume (fig 3 ) relative to placebo $(p=0.024)$; this effect was significant for both the 30 and $100 \mu \mathrm{g}$ doses $(\mathrm{p}<0.05$ with correction for multiple comparisons). In contrast, the postprandial total gastric volume was greater with placebo (median volume $817 \mathrm{ml}$ (IQR 775-870)) than with $30 \mu \mathrm{g}$ (median volume $693 \mathrm{ml}$ (IQR 617-745)) or $100 \mu \mathrm{g}$ octreotide (median volume $695 \mathrm{ml}$ (IQR 602-733)). Similarly, the change in postprandial volume (fig 4) relative to fasting was significantly lower with octreotide relative to placebo $(p<0.001)$, and this effect was also significant for both doses tested (both $\mathrm{p}<0.05$ with correction for multiple comparisons).

Postprandial volumes in the placebo treated group were not different between the first (0-16 minutes) and second (17-32 minutes) measurements in the postprandial period. In contrast, volumes were significantly lower during the second periods with both doses of octreotide (fig 5). 

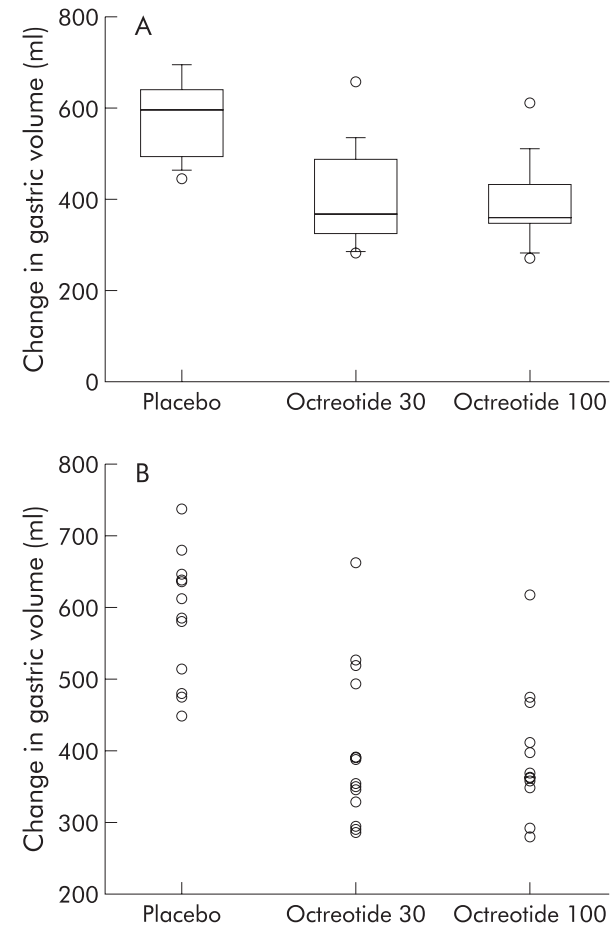

Figure 4 Effect of octreotide 30 and $100 \mu \mathrm{g}$ compared with placebo on change in gastric volume with ingestion of a standard $300 \mathrm{ml}$ Ensure meal. Note that both doses of octreotide reduced the postprandial increase in gastric volume.

\section{Maximum tolerated volume and postprandial symptoms}

Octreotide did not significantly alter the maximum volume ingested at the point of maximum satiation (placebo: median volume $1331 \mathrm{ml}$ (IQR 1184-1509); octreotide $30 \mu \mathrm{g}$ : $1335 \mathrm{ml}$ (IQR 1084-1540); and octreotide $100 \mu \mathrm{g}$ : $1384 \mathrm{ml}$ (IQR 12211895)), or the aggregate postprandial symptom score 30 minutes later (table 2). Of the individual symptoms which were analysed for descriptive purposes as secondary end points (table 2), only fullness was significantly reduced by octreotide ( $p=0.029$; fig 6 ), and this effect was significant only for the $100 \mu \mathrm{g}$ dose $(\mathrm{p}<0.05$ with correction for multiple comparisons).

\section{DISCUSSION}

This study has demonstrated the effects of octreotide on fasting and postprandial gastric volumes. Our study confirms retardation of gastric emptying of solids by octreotide, previously demonstrated in some reports. In addition, we have provided data on the effects on gastric emptying of two doses of octreotide that are commonly used to treat dumping syndrome in clinical practice. The effects of octreotide on postprandial sensation can be evaluated more thoroughly, in view of the observations on gastric emptying and volumes in the same participants.

Octreotide increases fasting gastric volume and this is consistent with the inhibitory effects of the somatostatin analogue on gastrointestinal contractility or tone in the stomach and elsewhere in the digestive tract. In a study of 13 male volunteers, Mertz and colleagues ${ }^{19}$ showed that higher doses $(1.25 \mu \mathrm{g} / \mathrm{kg}$ subcutaneously) of octreotide increased stomach volume responses to phasic distensions of an intragastric balloon (suggesting increased compliance) and the reduced sensation of fullness during volume based gastric distensions. However, the effects of octreotide on sensation were not replicated during ramp inflation by these ${ }^{19}$ or other authors. ${ }^{20}$ Our study showed that, under physiological conditions and in the absence of invasive intubation, octreotide increased fasting gastric volume, an effect which may reflect the ability of somatostatin to regulate neurotransmitter release, ${ }^{31}$ activate nitrergic mechanisms, ${ }^{18}$ or reduce enteric neuronal excitability by postjunctional effects. ${ }^{28} 32$

By way of contrast, the volume of the stomach after a standard $300 \mathrm{ml}$ Ensure meal was not larger with octreotide than with placebo treatment. In fact, the change in volume to the same Ensure volume and calorie load was, on average, $200 \mathrm{ml}$ smaller with each of the two octreotide doses than placebo. This might be considered paradoxical given the observed increase in fasting gastric volume. However, gastric emptying measurements based on planar (two dimensional) imaging do not accurately reflect actual intragastric volume; these measurements merely track the rate of emptying of the radioisotopic marker tagging the meal substrate. In contrast, the SPECT method provides an assessment of the radiolabelled circumference of the gastric wall (from which the
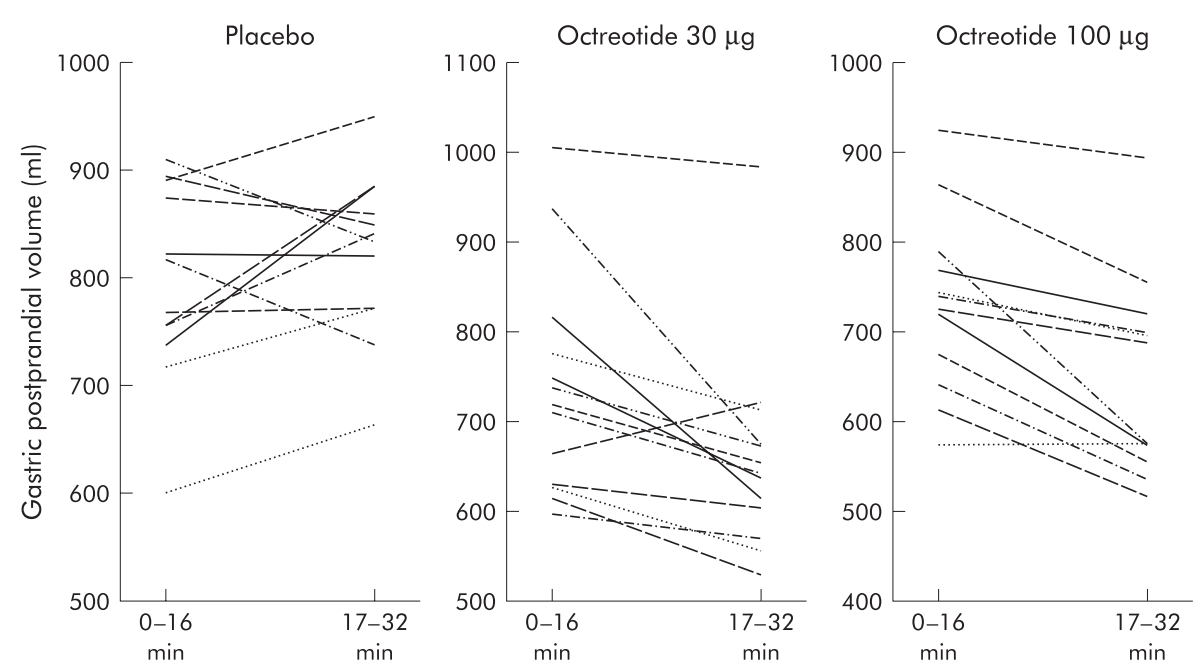

Figure 5 Comparison of postprandial volumes after octreotide 30 and $100 \mu \mathrm{g}$ compared with placebo during two postprandial measurements, 0-16 minutes (A) and 17-32 minutes (B) minutes after the meal. Whereas volumes were comparable during placebo treatment, note that volumes were higher in the first than in the second period when volunteers received octreotide. 
Table 2 Postprandial symptoms 30 minutes after a maximally tolerated volume of Ensure

\begin{tabular}{|c|c|c|c|}
\hline Symptom scores & Placebo group & Octreotide $30 \mu \mathrm{g}$ group & Octreotide $100 \mu \mathrm{g}$ group \\
\hline $\begin{array}{l}\text { Aggregate } \\
\text { Fullness* } \\
\text { Nausea† } \\
\text { Bloating } \ddagger \\
\text { Pain }\end{array}$ & $\begin{array}{l}178(152-219) \\
84(71-91) \\
40(15-58) \\
57(45-74) \\
11(2-28)\end{array}$ & $\begin{array}{l}179(179-227) \\
70(60-83) \\
14(0-30) \\
68(49-81) \\
14(1-35)\end{array}$ & $\begin{array}{r}127(75-250) \\
65(33-78)^{* *} \\
14(5-56) \\
40(26-64) \\
4(1-46)\end{array}$ \\
\hline \multicolumn{4}{|c|}{$\begin{array}{l}\text { Data are median scores (interquartile range). Maximum aggregate score }=400 ; \text { maximum individual score }=100 \text {. } \\
{ }^{*} p=0.029,{ }^{* *} p<0.05 \text { versus placebo (ANOVA on ranks with Dunn's test). } \\
\dagger p=0.10 \text { (ANOVA on ranks). } \\
\neq p=0.085 \text { (ANOVA on ranks). }\end{array}$} \\
\hline
\end{tabular}

volume is then calculated) rather than the intragastric content. The volume measured includes secreted fluids and swallowed air, not only the meal itself. It is conceivable that gastric emptying can be delayed without an increase in gastric volume (for example, if the tone of the stomach is not relaxed after the meal or if there is less gastric secretion or swallowed air). The postprandial total gastric volume was greater with placebo than with $30 \mu \mathrm{g}$ or $100 \mu \mathrm{g}$ octreotide, suggesting that the smaller change in gastric volume after the meal was not only the result of the higher fasting gastric volume with octreotide. Further studies are required to address the relative contributions of gastric tone and secretions to the apparent paradox between gastric emptying delay and lower change in gastric volume after the meal with octreotide treatment.

Careful review of the literature suggests there are mechanistic explanations that are consistent with the findings of decreased gastric volume and slower emptying with octreotide. The greater fasting volume with octreotide than placebo suggests that the effect of the somatostatin analogue results either by a direct effect (for example, by its postjunctional effects on enteric neuronal excitability) or through an inhibitory pathway (for example, by activating nitrergic neurones)..$^{182} 3132$ The normal increase in stomach volume in response to a meal represents a distension and nutrient mediated reflex. ${ }^{29} 33$ The reflex involves the release of peptides and other transmitters such as serotonin and cholecystokinin from the upper gastrointestinal mucosa, activation of vagal afferents, and stimulation of vagal efferents that activate intrinsic inhibitory nerves to induce gastric relaxation and enhance gastric volume.

The current studies do not permit a definitive characterisation of the site of action of octreotide. Somatostatin and octreotide inhibit release of many gastroenteropancreatic hormones in response to meal ingestion. ${ }^{5}$ The effects of octreotide may be, at least partly, mediated through effects

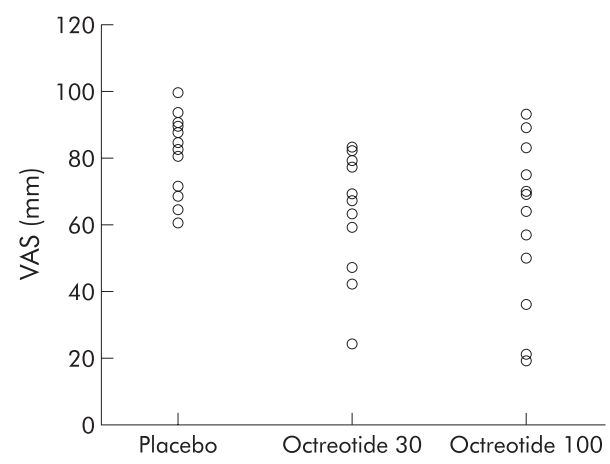

Figure 6 Effect of octreotide 30 and $100 \mu \mathrm{g}$ compared with placebo on fullness scores 30 minutes after ingestion of a fully satiating meal of Ensure meal. A scatterplot of all of the data is shown. Note that octreotide $100 \mu \mathrm{g}$ reduced fullness relative to placebo treatment. VAS, visual analogue scale. on afferent nerves. Thus experimental evidence using single fibre recordings from mesenteric and vagal afferents have shown that octreotide reduces afferent firing in response to distension. ${ }^{1718}$ This may result in the reduced volume response and reduced activation of antral contractility that normally leads to trituration and emptying of solid food.

Wall tension or afferent nerve function may both contribute to the level of sensation; ${ }^{34}$ Mertz and colleagues ${ }^{19}$ also suggested that the effects of octreotide on gastric sensation were partly attributable to the motor effects of octreotide on gastric compliance. We cannot exclude this effect given the significant effects on volume based distensions. In our study, maximum tolerated volumes of Ensure were not smaller, and postprandial symptoms were not higher relative to placebo treatment despite lower postprandial volume. These data suggest that postprandial sensation was not determined solely by postprandial gastric volume, and the data are more consistent with the effects of octreotide on afferent function, as previously shown in the rectum. ${ }^{15} 1630$

Another intriguing observation is that postprandial volumes were not different during the two postprandial measurements under placebo treatment. In contrast, with both octreotide doses, there were consistently lower gastric volumes during the second postprandial measurement. The latter observation may suggest that effects of octreotide on the mechanisms that result in increased gastric volume might change over time in the postprandial period. We do not believe this is due to the pharmacokinetic properties of octreotide $^{21}$ as the motor actions of the drug are virtually immediate after subcutaneous injection, and the pharmacodynamic actions are demonstrable for at least 2-4 hours after administration, as shown by the effects on gastric emptying of solids. Moreover, the inhibitory effect of octreotide on postprandial volume is greater in the second measurement relative to the first period. This would be opposite to what would be expected if the effects of the drug reflected only the lower circulating levels of octreotide in the second period. Another possible explanation is that there is a greater effect of octreotide on nutrient mediated activation of the accommodation reflex compared with inhibition of the volume increase in response to the mechanical distension of the stomach by the meal. This hypothesis requires further study.

An effect on sensory mechanisms is suggested by other observations in our study. Thus despite the very significant delay in gastric emptying of food and the reduced gastric volume change postprandially, administration of octreotide was associated with a similar maximum tolerated volume, aggregate symptom score, and reduced fullness score. To date, octreotide has been shown to reduce sensation during rectal and gastric distension studies in humans. ${ }^{14-16} 192030$ Formal studies that assess post food sensation are needed as octreotide also increases fasting gastric volume which may be associated with reduced meal induced satiation, ${ }^{35}$ and this might be beneficial for the treatment of functional upper 
gastrointestinal disorders associated with early satiation and weight loss. ${ }^{25}$

In summary, octreotide has important effects on stomach emptying, sensation, and volumes; this study in healthy individuals has provided novel insights that require further testing in disease states

\section{ACKNOWLEDGEMENTS}

This study was supported in part by grants R01 DK-54681 (MC) and K24 DK-02638 (MC) from the National Institutes of Health. We thank Mrs Cindy Stanislav for excellent secretarial assistance.

\section{Authors' affiliations}

A Foxx-Orenstein, M Camilleri, D Stephens, D Burton, Clinical Enteric Neuroscience Translational and Epidemiological Research (CENTER)

Program, Mayo Clinic, Rochester, MN, USA

\section{REFERENCES}

1 Csaba Z, Dournaud P. Cellular biology of somatostatin receptors. Neuropeptides 2001;35:12-13.

2 Haruma K, Wiste JA, Camilleri M. Effect of octreotide on gastrointestinal pressure profiles in health and in functional and organic gastrointestinal disorders. Gut 1994:35:1064-9.

3 von der Ohe MR, Camilleri M, Thomforde GM, et al. Differential regional effects of octreotide on human gastrointestinal motor function. Gut 1995;36:743-8.

4 Mourad FH, Gorard D, Thillainayagam AV, et al. Effective treatment of diabetic diarrhoea with somatostatin analogue, octreotide. Gut 1992;33:1578-80.

5 Myers MJ, Ghatei MA, Bloom SR. Effect of a new oral somatostatin analog (SDZ CO 611) on gastric emptying, mouth to cecum transit time, and pancreatic and gut hormone release in normal male subjects. J Clin Endocrinol Metab 1994:78:329-36.

6 O'Donnell UD, Watson AJM, Cameron D, et al. Effect of octreotide on mouthto-caecum transit time in healthy subjects and in the irritable bowel syndrome. Aliment Pharmacol Ther 1990;4:177-82.

7 O'Keefe SJ, Haymond MW, Bennet WM, et al. Long-acting somatostatin analogue therapy and protein metabolism in patients with jejunostomies. Gastroenterology 1994;107:379-88.

8 Geer RJ, Richards WO, O'Dorisio TM, et al. Efficacy of octreotide acetate in treatment of severe postgastrectomy dumping syndrome. Ann Surg 1990:212:678-87.

9 Soudah HC, Hasler WL, Owyang C. Effect of octreotide on intestinal motility and bacterial overgrowth in scleroderma. N Engl J Med 1991;325:1461-9.

10 Peeters TL, Janssens J, Vantrappen GR. Somatostatin and the interdigestive migrating motor complex in man. Regul Pept 1983;5:209-17.

11 Neri M, Cuccurullo F, Marzio L. Effect of somatostatin on gallbladder volume and small intestinal motor activity in humans. Gastroenterology 1990;98:316-21

12 von der Ohe M, Layer P, Wollny C, et al. Somatostatin 28 and coupling of human interdigestive intestinal motility and pancreatic secretion. Gastroenterology 1992;103:974-81.

13 Patch D, Burroughs AK. Pharmacological treatment of portal hypertension. Prog Liver Dis 1995; 13:269-92.
14 Hasler WL, Soudah HC, Owyang C. A somatostatin analogue inhibits afferent pathways mediating perception of rectal distention. Gastroenterology 1993; 104:1390-7.

15 Plourde V, Lembo T, Shui Z, et al. Effects of the somatostatin analogue octreotide on rectal afferent nerves in humans. Am J Physiol 1993;265:G742-51

16 Hasler WL, Soudah HC, Owyang C. Somatostatin analog inhibits afferent response to rectal distention in diarrhea-predominant irritable bowel patients. J Pharmacol Exp Ther 1994;268:1206-11.

17 Su X, Burton MB, Gebhart GF. Effects of octreotide on responses to colorectal distension in the rat. Gut 2001;48:676-82.

18 Abdu F, Hicks GA, Hennig G, et al. Somatostatin sst(2) receptors inhibit peristalsis in the rat and mouse jejunum. Am J Physiol Gastrointest Liver Physiol 2002;282:G624-33.

19 Mertz H, Walsh JH, Sytnik B, et al. The effect of octreotide on human gastric compliance and sensory perception. Neurogastroenterol Motil 1995; 7:175-85

20 Mearadii B, Straathof JW, Biemond I, et al. Effects of somatostatin on proximal gastric motor function and visceral perception. Aliment Pharmacol Ther 1998; 12:1163-9.

21 Chanson P, Timsit J, Harris AG. Clinical pharmacokinetics of octreotide. Therapeutic applications in patients with pituitary tumors. Clin Pharmacokinet 1993;25:375-91.

22 Cremonini F, Mullan BP, Camilleri M, et al. Performance characteristics of scintigraphic transit measurements for studies of experimental therapies. Aliment Pharm Ther 2002;16:1781-90.

23 Kuiken SD, Samsom M, Camilleri M, et al. Development of a test to measure gastric accommodation in humans. Am J Physiol 1999;277:G1217-21.

24 Bouras EP, Delgado-Aros S, Camilleri M, et al. SPECT imaging of the stomach: comparison with barostat and effects of sex, age, body mass index, and fundoplication. Gut 2002;51:781-6.

25 Kim D-Y, Delgado-Aros S, Stephens DA, et al. Noninvasive measurement of gastric accommodation in patients with idiopathic nonulcer dyspepsia. Am J Gastroenterol 2001;96:3099-105.

26 Tack J, Piessevaux $\mathrm{H}$, Coulie B, et al. Role of impaired gastric accommodation to a meal in functional dyspepsia. Gastroenterology 1998;1 15:1346-52.

27 Chial HJ, Camilleri C, Delgado-Aros S, et al. A nutrient drink test to assess maximum tolerated volume and postprandial symptoms: effects of gender, body mass index and age in health. Neurogastroenterol Motil 2002:14:249-53.

28 Mihara S, North RA, Surprenant A. Somatostatin increases an inwardly rectifying potassium conductance in guinea-pig submucous plexus neurones. $J$ Physiol (Lond) 1987;390:335-55.

29 Azpiroz F, Malagelada JR. Gastric tone measured by an electronic barostat in health and postsurgical gastroparesis. Gastroenterology 1987;92:934-43.

30 Bradette M, Delvaux M, Staumont G, et al. Octreotide increases thresholds of colonic visceral perception in IBS patients without modifying muscle tone. Dig Dis Sci 1994:39:1171-8.

31 Yau WM, Lingle PF, Youther ML. Modulation of cholinergic neurotransmitter release from myenteric plexus by somatostatin. Peptides 1983;4:49-53.

32 Katayama Y, North RA. The action of somatostatin on neurones of the myenteric plexus of the guinea-pig ileum. J Physiol (Lond) 1980;303:315-23.

33 Grundy D. Neuroanatomy of visceral nociception: vagal and splanchnic afferent. Gut 2002;51(suppl1):i2-5.

34 Camilleri M, Coulie B, Tack JF. Visceral hypersensitivity: facts, speculations and challenges. Gut 2001;48:1251-31.

35 Delgado-Aros S, Chial HJ, Burton DD et al. Increased caloric intake and decreased postprandial fullness with increased BMI are related to greater fasting gastric volume: a controlled study of 170 volunteers. Gastroenterology 2003;124:A31. 